\title{
Фемтосекундная лазерная запись астигматическим гауссовым пучком периодических структур на пленке хрома
}

\author{
А.В. Достовалов $^{1,2, *}$, В.С. Терентьев ${ }^{2}$, К.А. Бронников ${ }^{2}$, К.А. Окотруб ${ }^{2}$, \\ Д.А. Белоусов ${ }^{2}$ В.П. Корольков ${ }^{1,2}$, С.А. Бабин ${ }^{1,2}$ \\ ${ }^{1}$ Новосибирский государственный университет, Новосибирск \\ ${ }^{2}$ Институт автоматики и электрометрии СО РАН, Новосибирск \\ "E-mail: dostovalov@iae.nsk.su
}

DOI:10.31868/RFL2018.198-199

Образование упорядоченных периодических оксидных структур в области фокусировки лазерного излучения при обработке поверхности титановых металлических пленок исследовалось при нс [1] и фс [2, 3] длительности импульсов. Было установлено, что период данных структур $\Lambda<\lambda$, где $\lambda$ - длина волны падающего лазерного излучения, при этом ориентация структур параллельна направлению поляризации падающего лазерного излучения. Поскольку основную роль в образовании данных структур играет термически стимулированная химическая реакция окисления, то данный тип структур принято называть «термохимическими лазерно-индуцированными периодическими поверхностными структурами» (ТЛИППС). Помимо Ті исследовалось образование данных структур на поверхности пленок $\mathrm{Cr}$, $\mathrm{Ni}$ и $\mathrm{NiCr}$ под действием фс лазерных импульсов [4]. Зависимость периода ТЛИППС от химического состава оксида была продемонстрирована в [5].

В представленных выше работах при создании ТЛИППС использовался радиально симметричный гауссов пучок с диаметром менее 20 мкм. При этом скорость сканирования пучка для формирования упорядоченных структур была небольшой (от 1 до $10 \mathrm{m \kappa м/c),} \mathrm{что} \mathrm{ограничивает} \mathrm{практическое} \mathrm{применение}$ данного метода создания структур. Для увеличения производительности записи требуется использовать гауссов пучок с большим диаметром перетяжки. Однако при использовании фс лазеров с низкой максимальной энергией в импульсе данный подход не реализуем, поскольку двойное увеличение диаметра пучка требует увеличения энергии импульса в 4 раза для обеспечения постоянства уровня интенсивности излучения при записи. Альтернативный путь увеличения производительности - это использование астигматического гауссова пучка, у которого поперечное сечение перетяжки представляет собой эллипс с отношение полуосей отличным от 1 . В данном случае при увеличении размера большей полуоси пучка в 2 раза энергия также увеличивается в 2 раза.

В работе представлены результаты по созданию ТЛИППС на поверхности $\mathrm{Cr}$ пленки толщиной 30 нм с использованием астигматического гауссова пучка ИК фс лазера с длиной волны 1026 нм при различных экспериментальных параметрах: скорость сканирования (100-3000 мкм/с), частоте следования импульсов $(2,20,200$ кГц) и мощности излучения (150-350 мВт). Фокальное пятно в форме эллипса с соотношением сторон 1:10 (Рис. 1) было сформировано с помощью цилиндрической линзы и сферической фокусирующей линзы с $f=50$ мм. При этом максимальный размер области модификации (вдоль большой оси эллипса) при воздействии $2 \times 10^{5}$ импульсов составил 110 мкм и период структур 680 нм. На рис. 2 представлены результаты по формированию ТЛИППС в зависимости от скорости сканирования в диапазоне 100 мкм/с - 2000 мкм/с при фиксированной мощности излучения 240 мВт. 
Для количественного анализа однородности структуры в зависимости от скорости сканирования использовался параметр DLOA (dispersion in the LIPSS orientation angle) $\Delta \theta[6]$, который характеризует угловое размытие при двумерном преобразовании Фурье СЭМ изображений структур. Из представленных результатов следует, что при минимальной скорости сканирования $\Delta \theta=2^{\circ}$, что свидетельствует о высокой степени упорядоченности структур. Далее при увеличении скорости сканирования до 300 мкм/с этот параметр растет до $5.5^{\circ}$ и существенно не изменяется при последующем росте скорости сканирования (рис. 2 д). Таким образом, увеличение скорости сканирования в процессе формирования ТЛИППС приводит к ухудшению прямолинейности (однородности) полученных структур.

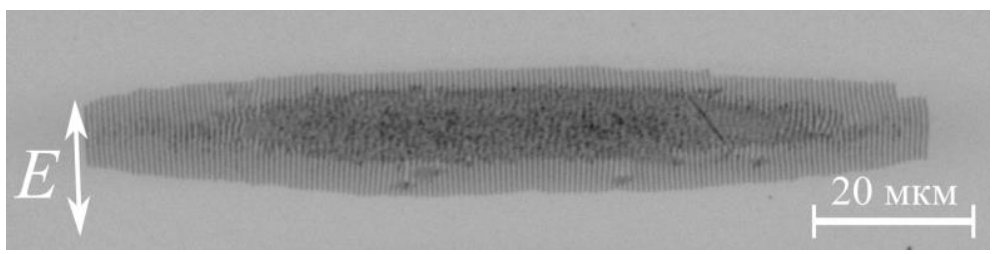

Рис. 1. Форма модификации при воздействии астигматического гауссова пучка $(\mathrm{P}=270$ мВт).
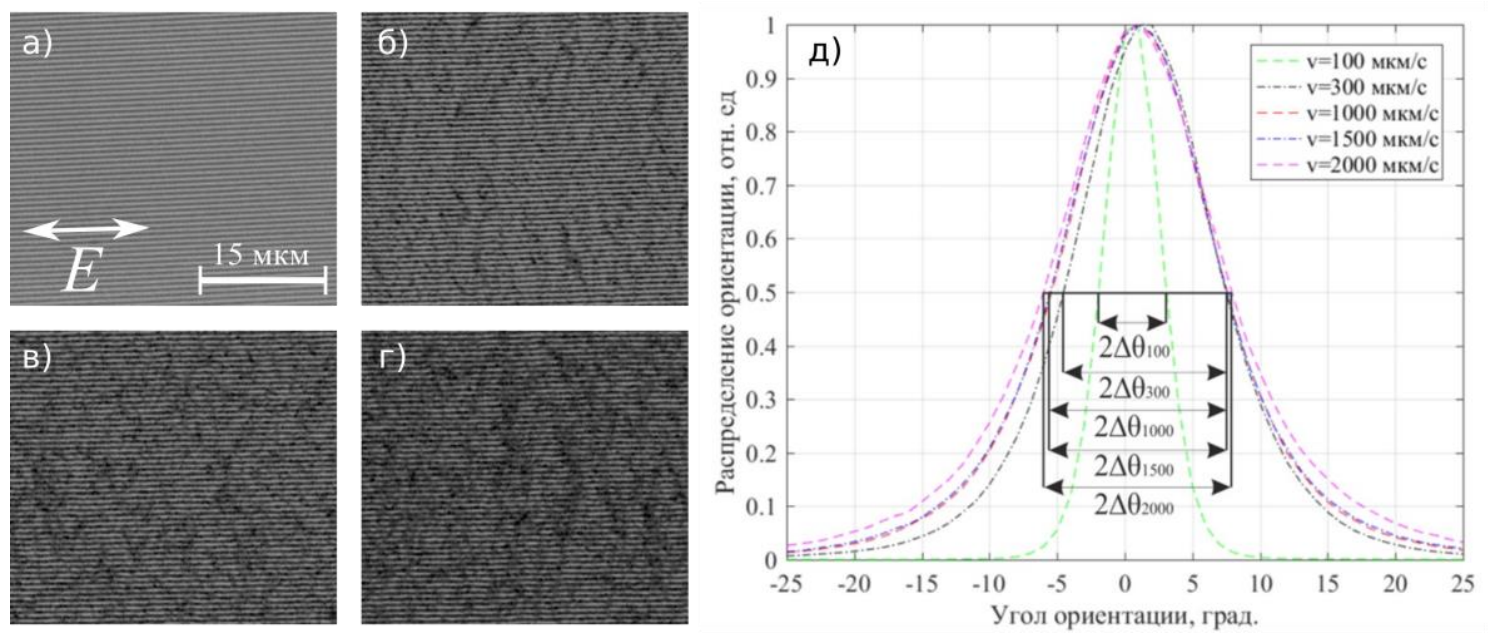

Рис. 2. СЭМ изображение ТЛИПСС, сформированные при $\mathrm{P}=240$ мВт и различной скорости сканирования: 100 мкм/с (а), 300мкм/с (б), 1500 мкм/с (в), 2000 мкм/с (г). Зависимость DLOA от скорости сканирования (д).

Продемонстрирован способ создания ТЛИППС астигматическим гауссовым пучком, который позволяет повысить скорость сканирования при записи структур до 100-2000 мкм/с при поперечном размере области модификации $\approx 100$ мкм. Анализ упорядоченности структур свидетельствует об ухудшении упорядоченности с ростом скорости сканирования при формирования ТЛИППС.

Работа выполнена при поддержке РФФИ (грант 16-32-60096).

\section{Литература}

[1] S. Camacho-López et al, Appl. Surf. Sci. 255, 3028-3032 (2008)

[2] B. Öktem et al, Nat. Photonics 7, 897-901 (2013)

[3] A.V. Dostovalov et al, Appl. Phys. B, 123:30, 1-9 (2017)

[4] A.V. Dostovalov et al, Quantum Electron., 7, 631-637 (2017)

[5] A.V. Dostovalov et al, Opt. Express 26, 7712-7723 (2018)

[6] I. Gnilitskyi et al, Scientific Reports. 7, 8485 (2017) 